\section{The 'neurocentric circle'}

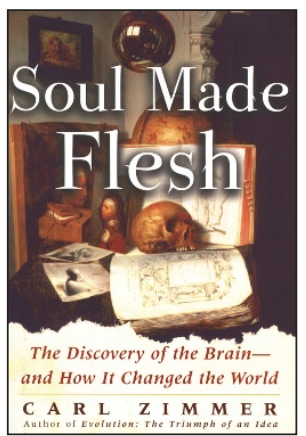

Soul Made Flesh: The Discovery of the Brain-and How it Changed the World

by Carl Zimmer

Free Press, 2004

384 pp., hardcover, $\$ 26.00$

ISBN 0743230388

Reviewed by Marco Piccolino

With Soul Made Flesh: The Discovery of the Brain-and How It Changed the World, Carl Zimmer (author of Parasite Rex) provides a vivid picture of a colorful phase of scientific development in seventeenth-century England. The book largely centers on the figure of Thomas Willis, a physician and anatomist whom most medical students know indirectly because of the 'circle of Willis,' the arterial structure at base of the brain which insures appropriate blood flow to the 'organ of soul,' the brain.

Willis was the author of a series of studies on brain anatomy, culminating in 1664 with the publication of De Cerebri Anatome, a milestone in the development of what we now call the 'neurosciences'- a word introduced about 30 years ago by Francis $\mathrm{O}$. Schmitt. More than any other, we owe Willis credit for the first modern images of central nervous system anatomy-images magnificently drawn by Christopher Wren, on the way to becoming the major English architect of his time. With Richard Boyle, John Wilkins and others, Wren associated with the circle of 'natural philosophers' that collaborated with Willis in Oxford-a 'circle of Willis' of a different kind. Some of them went on to found the Royal Society (the scientific academy which, for the next centuries, would have a fundamental role in the development of English science).

In contrast to the previous representations of the brain that flourished after the renewal of anatomical studies in the scientific Renaissance-generally more concerned with aesthetics-Willis' work was clearly the expression of a new research attitude, emerging with the scientific revolution of the seventeenth century. Willis and his associates aimed to find the plan of organization of the brain, convinced that the structural aspects of organisms could be explained on the basis of mechanical or chemical operations. This was a breakthrough in the conception of the higher functions of the nervous system, at the time still dominated by the doctrines developed in the Hellenistic period by Galen of Pergamum in Asia Minor. Galen maintained that the hollow parts of the brain, the

Marco Piccolino is in the Department of Biology and Center for Neurosciences, University of Ferrara, Ferrara, Italy.

email: pic@dns.unife.it cerebral ventricles, were the central sites of the circulation of the 'animal spirits,' elusive messengers of the operation of soul. The brain substance itself had only a secondary, protective role (which accounts for the term 'cortex'-rind-used to designate the external part of the brain).

According to Zimmer, it is mainly through Willis' endeavor that "soul was made flesh." Zimmer makes the bold-and in my opinion, perhaps not totally justified-claim that Willis and his associates initiated the 'Neurocentric Age,' an age in which we still live, "in which the brain is central not only to the body but to our conception of ourselves." Throughout the book, Zimmer establishes a link between the investigations of Willis (and of the scientists of his age) and modern achievements in neuroscience based on approaches such as electrophysiology, imaging and cognitive studies.

The book is written in an engaging way and the scientific descriptions are masterfully inserted into the context of a complex and dramatic phase of English history. Zimmer describes how the considerable religious and politic turmoil of the era affected the protagonists of this scientific revolution, but did not tame their intellectual freedom or their hunt for knowledge directly derived from the 'book of Nature' rather than from the tradition of Galen, Aristotle and Hippocrates. The combination of intellectual vivacity and dramatic political conditions reminds us of a famous line spoken by Orson Welles in The Third Man:

"You know what the fellow said: In Italy for 30 years under the Borgias they had warfare, terror, murder and bloodshed, but they produced Michelangelo, Leonardo da Vinci and the Renaissance. In Switzerland they had brotherly love - they had 500 years of democracy and peace, and what did that produce? The cuckoo clock."

Paradoxical as they are, such words might perhaps authorize some intellectual optimism in our present world dominated by political instability, wars, terrorism, and religious and cultural conflicts.

I have greatly enjoyed reading Zimmer's book and I would recommend it to scientists and to members of the general public interested in some of the paths leading to today's understanding of the brain. Nevertheless I have some criticisms, particularly because Zimmer keeps out of the scene many scientists who contributed to the revolution of life sciences in the seventeenth century and to the progress of nervous and muscular physiology (among them outstanding figures such as Francis Glisson, Jan Swammerdan, William Croone and Niels Stensen). I would also not endorse Zimmer's claim that Thomas Hobbes (together with William Harvey, another of the important dramatis personae of this book), by publishing Leviathan, "had essentially invented political science." At the time of Hobbes' masterpiece, political science was already a rather well established discipline, as the Principe of Niccolò Machiavelli had appeared in print more than a century before (not to mention works by Guicciardini, Botero, Bodin and others). In this and other aspects, it seems Zimmer's book is less a systematic historical account of the way "soul was made flesh" in seventeenth-century Europe, and more a fascinating play concentrated on an English scientist and his 'circle.' 